\title{
O acolhimento no cuidado à família numa unidade de terapia intensiva
}

\author{
User embracement in care for families at an intensive care unit \\ La acogida en el cuidado a la familia en una unidad de cuidados intensivos
}

\author{
Silvia da Silva Santos Passos'; Juliana Oliveira da Silva ${ }^{\text {II }}$; Valdenice dos Santos Santana III; \\ Vanessa Marques do Nascimento Santos ${ }^{I V}$; Alvaro Pereira ; Luciano Marques dos Santos ${ }^{V I}$
}

\begin{abstract}
RESUMO: Trata-se de um estudo qualitativo e descritivo, com o objetivo de descrever como a enfermeira se apropria do acolhimento no cuidado à família na unidade de tratamento intensivo (UTI). Os dados foram obtidos por meio de entrevistas semiestruturadas aplicadas a seis enfermeiras que atuavam numa unidade de terapia intensiva de um hospital público no interior da Bahia, nos meses de maio e junho de 2011. Em seguida, os depoimentos foram submetidos à análise de conteúdo temática, a partir dos quais emergiram três categorias: Acolhendo a família na UTI; Relacionando-se com as famílias na UTI; e Cuidando da família na UTI. Os resultados destacam que a enfermeira compreende a família como unidade do cuidado, mas por não sentir-se preparada, o acolhimento se restringe a aplicar o histórico e anamnese na admissão e atualizar informações sobre o estado clínico dos pacientes durante as visitas.
\end{abstract}

Palavras-Chave: Unidade de terapia intensiva; enfermagem familiar; acolhimento; relações enfermeiro-paciente.

ABSTRACT: This qualitative, descriptive study described how nurses appropriate user embracement in caring for families in the ICU. Data were collected through semi-structured interviews of six nurses working in the ICU of a public hospital in Bahia from May to June 2011. From thematic content analysis of the transcripts, three categories emerged: welcoming the family in the ICU; relating to families in the ICU; and caring for families in the ICU. The results highlight that nurses understand the family as a unit of care, but feel unprepared in user embracement, which is thus restricted to applying case history and anamnesis on admission, and providing updates on patient clinical condition during visits.

Keywords: Intensive care unit; family nursing; user embracement; nurse-patient relations.

RESUMEN: Se trata de un estudio cualitativo y descriptivo cuyo objetivo consiste en describir cómo la enfermera se hace cargo de la acogida en el cuidado a la familia en una unidad de cuidados intensivos (UCI). Los datos han sido recolectados a través de entrevistas semiestructuradas aplicadas a seis enfermeras que trabajaban en la unidad de cuidados intensivos de un hospital público de Bahía, en mayo y junio de 2011. A continuación, se han sometido las declaraciones al análisis de contenido y han surgido tres categorías: Acogiendo la familia en la $\mathrm{UCl}$; Relacionándose con las familias en la $\mathrm{UCl}$; y Cuidando de la familia en la UCI. Los resultados ponen de manifiesto que la enfermera entiende la familia como unidad de atención pero, por no sentirse lista, la acogida se limita a verificar la historia clínica y la anamnesis al ingreso y actualizar la información sobre el estado clínico de los pacientes durante las visitas.

Palabras Clave: Unidades de cuidados intensivos; enfermería para la familia; acogida; relaciones enfermero-paciente.

\section{INTRODUÇÃO}

Os pacientes que precisam de cuidados intensivos e se encontram em estado grave necessitam de um ambiente com suporte tecnológico que favoreça seu acompanhamento e recuperação. A unidade de terapia intensiva (UTI) é diferente de outras unidades de internação. $O$ tratamento implantado nesse ambiente é considerado agressivo e invasivo, traduzindo-se por alta intensidade e complexidade de eventos e situações, tanto para o paciente como para sua família. Pode ser menos hostil se os profissionais de saúde perceberem cada ser humano como um indivíduo único, com necessidades específicas ${ }^{1}$.

A UTI é considerada o local no qual se concentram grandes recursos tecnológicos, tornando-se um

IEnfermeira. Mestre em Enfermagem. Professora Assistente do Departamento de Saúde da Universidade Estadual de Feira de Santana. Doutoranda em Enfermagem pela Escola de Enfermagem da Universidade Federal da Bahia. Brasil.E-mail: ssspassos@yahoo.com.br

IIEnfermeira. Especialista em Enfermagem Intensiva pela Faculdade Nobre de Feira de Santana. Professora do Centro Técnico Profissional. Enfermeira do Programa de Saúde da Família de Feira de Santana. Bahia, Brasil. E-mail: julianna sillva@hotmail.com.

IIIEnfermeira. Especialista em Enfermagem Intensiva pela Faculdade Nob̄re de Feira de Santana. Coordenadora da Equipe multidisciplinar de Saúde Indígena Missão Evangélica, Ministério da Saúde. Feira de Santana, Bahia, Brasil. E-mail: valdenicesantanna@gmail.com.

${ }^{\mathrm{IV}}$ Enfermeira. Especialista em Enfermagem Intensiva pela Faculdade Nobre de Feira de Santana. Coordenadora de Enfermagem do Hospital Municipal José Maria de Magalhães Neto em São Gonçalo dos Campos. Bahia, Brasil. E-mail: nessa.tico@hotmail.com.

vEnfermeiro. Doutor em Enfermagem. Professor Adjunto IV da Escola de Enfermagem da Universidade Federal da Bahia.E-mail: alvaro_pereira_ba@yahoo.com.br VIEnfermeiro. Mestre em Enfermagem. Professor Auxiliar do Curso de Enfermagem da Universidade Estadual de Feira de Santana. Bahia, Brasil. E-mail: lucmarxenfo@yahoo.com.br 
ambiente cercado de dor e sofrimento. Neste espaço, prevalecem a técnica e a máquina e sua dinâmica envolve habilidades e conhecimentos tecnológicos específicos e especializados.

Entretanto, aliar os recursos tecnológicos da UTI aos valores humanitários tem se constituído um desafio para a equipe de saúde, pois, nesse espaço, os profissionais permanecem em constante interação com a tecnicidade do cuidado, essencial para a manutenção da vida e a proximidade da morte.

Os valores humanísticos no cuidado na UTI são percebidos pelo envolvimento dos profissionais de saúde com o paciente e sua família, sendo possível, neste momento, dosar, de forma equilibrada, as necessidades emocionais e o uso da tecnologia ${ }^{2}$.

Para clientes e familiares, a hospitalização na UTI é um acontecimento estressante e singular provocado por fatores como: o risco de morte, a incerteza quanto ao tratamento e recuperação, o medo quanto à possibilidade de não se obter sucesso ou um bom prognóstico e do desconhecido, a ansiedade, tristeza, sofrimento, impotência e também a grande limitação pelo afastamento dos familiares desse cenário ${ }^{3}$.

Nesse sentido, os familiares, diante da internação de seu parente na UTI, apresentam sintomas, incluindo depressão, ansiedade e estresse pós-traumático. A proximidade ao paciente, o recebimento de informações adequadas, a oportunidade de expressar seus sentimentos e de obter respostas às suas dúvidas aumentam a satisfação da família ${ }^{4}$.

Por isso, é fundamental a utilização de estratégias que possam amenizar o sofrimento da família que possui um ente querido hospitalizado em cuidados intensivos. Dessa forma, a incorporação, na prática, do acolhimento efetivo vai permitir criar uma relação estreita entre o profissional de saúde e aquele que precisa de cuidado, para que o foco não seja somente a doença. Estimular essa prática na UTI deve ser imprescindível já que, nesse espaço, se concentra um verdadeiro arsenal tecnológico em detrimento das relações interpessoais.

Os familiares, na maioria das vezes, apresentam-se perdidos por não conhecerem a rotina da UTI e não terem esclarecimento diante do profissional de saúde. $\mathrm{O}$ enfermeiro, que é responsável pela assistência e cuidado, possui uma sobrecarga de trabalho e nem sempre tem oportunidade para esclarecer as dúvidas da família ${ }^{5}$.

Nesse contexto, o interesse por esta temática ocorreu pela percepção, durante as atividades acadêmicas, de que os familiares permanecem distantes da equipe de enfermagem. Entendendo que a relação entre familiares e a enfermagem deva envolver o cuidado humanizado, a questão norteadora neste estudo é: Como a Enfermeira utiliza o acolhimento no cuidado à família na UTI de um hospital Público do interior da Bahia? Assim, o objetivo do estudo foi descrever como a enfermeira se apropria do acolhimento no cuidado à família na UTI de um hospital público, no interior da Bahia.

O acolhimento faz parte da Política Nacional de Humanização, que tem o papel de garantir que os cidadãos sejam ouvidos com atenção e acolhidos para que tenham um acesso adequado a todas as unidades da rede pública de saúde, podendo esclarecer suas dúvidas e amenizar seus medos e anseios com o devido atendimento às suas necessidades respeitando, dessa forma os seus direitos ${ }^{6}$.

$\mathrm{O}$ ato de acolher torna-se um caminho para os profissionais que desejam o resgate do cuidado humanístico na saúde².

\section{REVISÃo DE LITERATURA}

Acolher implica a escuta, significa tentar compreender o que o indivíduo diz - o que se traduz em saber ouvir. $\mathrm{O}$ ato de acolher e de ouvir cria uma relação entre os envolvidos no processo, que precisam interagir entre si, visando ao engajamento necessário para a concretização do verdadeiro ato de cuidar?

$\mathrm{O}$ acolhimento implica que cada profissional partícipe no processo de saúde assuma seu protagonismo, esteja aberto e valorize o encontro com o outro, com uma postura de escuta e compromisso. $\mathrm{O}$ trabalho deve ser desenvolvido por meio de uma equipe, composta por diversos profissionais, de maneira a facilitar a construção coletiva de propostas e a elaboração de projetos terapêuticos. Os serviços devem ser reorganizados, para possibilitar essa mudança e garantir que os profissionais também sejam acolhidos em suas necessidades profissionais ${ }^{8}$.

A busca da melhoria dos cuidados para pacientes em estado crítico com uma abordagem holística tem sido evidente. $O$ cuidado centrado no paciente e na sua família tem aumentado e visa melhorar a qualidade do tratamento, bem como a satisfação do paciente e da família ${ }^{4}$. Unidades de cuidados intensivos são, provavelmente, um dos lugares mais difíceis e estressantes em um hospital em termos de ansiedade e depressão entre os familiares de pacientes internados em $\mathrm{UTI}^{9}$.

Por isso, acolher a família em cuidados intensivos precisa ser uma prática constante como um cuidado relevante na UTI. A enfermagem necessita ressignificar sua importância, pois poderá incentivar a humanização por meio de iniciativas educativas.

Assim, receber informações sobre seu familiar na UTI, manter contato com o ambiente tecnológico, os equipamentos, a incerteza e a falta de comunicação com os profissionais são fatores que demandam insegurança, ansiedade e estresse nas famílias de pacientes internados na UTI ${ }^{10}$.

Nesse contexto, o acolhimento é uma relação humanizadora, de trocas, é uma atividade que inclui o sujeito e seu contexto social, a ambiência, a organização 
do serviço, a relação entre profissionais e usuários do serviço. Assim, o acolhimento é essencial para o diálogo entre os profissionais, pacientes e suas famílias².

É também um dispositivo de intervenção que possibilita analisar o processo de trabalho em saúde com foco nas relações e que pressupõe a mudança das relações profissional/usuário/rede social e profissional/ profissional por meio de parâmetros técnicos, éticos, humanitários e de solidariedade, reconhecendo o usuário como sujeito e como participante ativo no processo de produção da saúde ${ }^{11}$.

Desse modo, a humanização do atendimento em saúde, principalmente na UTI, depende das condições de trabalho dos profissionais, bem como de suas competências e habilidades técnicas, inclusive as relações humanas. A humanização no cuidar em enfermagem é indispensável para estabelecer a interação e o relacionamento com os usuários dos serviços de saúde, incluindo os seus familiares ${ }^{12}$.

Sentir-se acolhido, para alguns familiares, é ter apoio e atenção de cada profissional, é perguntar e encontrar a resposta, mesmo que aquela não seja uma resposta desejada. A humanização visa colocar em prática a produção dos cuidados em saúde capazes de conciliar a melhor tecnologia disponível com a promoção de acolhimento nos espaços de trabalho favoráveis ao bom exercício técnico e a satisfação dos profissio $\neg$ nais e usuários ${ }^{13}$.

$\mathrm{Na}$ tentativa de enfraquecer o modelo vigente e fortalecer as relações entre usuários dos serviços de saúde e os profissionais de saúde, com foco na humanização do serviço hospitalar, o Ministério da Saúde, em 2000, criou o Programa Nacional de Humanização de Assistência Hospitalar (PNHAH). Tal iniciativa engloba ações integradas que viabilizam a melhoria na qualidade e eficácia dos serviços prestados, objetivando o aprimoramento das relações interpessoais. As ações humanizadas, nesse sentido, visam à integração da eficiência técnica científica, a ética, o respeito e as necessidades dos clientes ${ }^{6}$. Esse programa aborda a humanização como um todo, não há um direcionamento para atividades específicas como nas unidades de cuidados intensivos.

Reorganizar o cenário de trabalho cujas ações ainda estão centradas no modelo tecnicista, voltado para a doença e não para o sujeito e quase que exclusivamente para a pessoa internada, desconsiderando o seu familiar, é um trabalho árduo e um desafio para a enfermagem, em especial a que atua em unidades de alta complexidade, como a UTI².

Assim, devem ser consideradas as duas bases de apoio para a enfermagem - a complexidade do cuidado na UTI e o valor da vida como sustentação moral e ética do seu trabalho. Essa prática é entendida como o ato de acolher. Desse modo, valorizar o acolhimento torna-se um caminho para os profissionais que desejam o resgate do cuidado humanístico na saúde ${ }^{4}$.

\section{Metodologia}

Trata-se de um estudo descritivo com abordagem qualitativa, realizado na UTI Adulto de um hospital público no interior da Bahia. Os sujeitos do estudo foram seis enfermeiras assistenciais da UTI, cujo trabalho permite algum contato com familiares de pacientes hospitalizados.

Os dados foram coletados nos meses de maio e junho de 2011, por meio de entrevistas semiestruturadas, sendo utilizado um roteiro com o intuito de responder à questão norteadora: Como a enfermeira utiliza o acolhimento no cuidado à família na UTI?

A coleta de dados foi iniciada após a aprovação pelo Comitê de Ética e Pesquisa com Seres Humanos da Faculdade Maria Milza, cujo protocolo é o de número 048/2011, respeitando-se a Resolução nº 196/96 do Conselho Nacional de Saúde. Todas as participantes assinaram o Termo de Consentimento Livre e Esclarecido em duas vias e foram identificadas por códigos. $\mathrm{O}$ código foi representado pela categoria profissional (ENF) e o número da ordem de realização das entrevistas.

Os depoimentos foram gravados após a autorização das entrevistadas e, posteriormente, foram transcritos pelas pesquisadoras. Os dados foram tratados, utilizando-se a análise de conteúdo temática ${ }^{14}$, que pressupõe algumas etapas, como: a pré-análise, com destaque para as falas dos sujeitos e o acolhimento no cuidado realizado pela enfermeira à família na UTI, por meio da leitura flutuante de todo material coletado.

Na fase de organização, procurou-se o tema ou regularidade recorrente, que envolveu a extração das unidades de registro das entrevistas. Foi elaborado um sistema de categorização que consistiu no agrupamento dos dados semelhantes e diferentes dos conteúdos das falas. Dessa forma, a categorização possibilitou definir três categorias: o acolhimento à família na UTI; o relacionamento com as famílias na UTI; e o cuidado à família na UTI, que são discutidas a seguir.

\section{Resultados e Discussão}

acolhimento na UTI em estudo não parece ser utilizado pelas enfermeiras entrevistadas no cuidado à família que vivencia o processo de doença e de hospitalização de um de seus membros, já que está associado a projetos institucionais ou atitudes pessoais.

\section{Categoria 1 - Acolhendo a família na UTI}

Para os familiares de pacientes internados na UTI, o acolhimento ainda não é uma condição comum, um compartilhamento de saberes e conhecimentos em saúde nesse espaço. $\bigcirc$ reconhecimento das enfermeiras investigadas sobre o acolhimento das famílias na UTI parece ser uma unanimidade, embora demonstrem certa dificuldade em acolher, orientar os familiares. 
Isso parece contraditório, pois destacam que, no momento, não está sendo feito nada sobre acolhimento, como evidenciado por uma das entrevistadas:

Bom, como acolhimento a gente não tem feito nenhum projeto, nenhum trabalho, mas dentro da unidade, algumas enfermeiras e alguns técnicos têm como acolhimento - o conversar, o tranquilizar, o tirar dúvidas, mas a tecnologia tira a gente dessa atividade, porque a gente fica preocupada com a parte de controle, mecanicista. (ENF 1)

A prioridade atribuída ao acolhimento, de acordo com a entrevistada, refere-se aos equipamentos utilizados para o atendimento imediato e monitorização dos pacientes críticos. A relação dos trabalhadores da saúde com o paciente hospitalizado e seus familiares é verticalizada, centrada no conhecimento estruturado (fazer técnico, maquinários, instrumental, normas e rotinas). Há pouca valorização da relação humana, tornando-a simplificada e fragmentada, com o cuidado direcionado somente para os aspectos físicos ${ }^{15}$.

- cuidado de enfermagem e a tecnologia estão interligados, pois o exercício da profissão está comprometido com princípios, leis e teorias, e a tecnologia pode ser compreendida como a expressão desse conhecimento científico e em sua própria transformação ${ }^{16}$.

No entanto, observa-se uma contradição na aplicabilidade do conceito de acolhimento à família, entre as entrevistadas, mencionadas a seguir, quando uma delas só pergunta o nome do paciente que vai ser internado, passando qualquer tipo de orientação para outros profissionais, enquanto a outra entrevistada confunde a entrevista da admissão do paciente como uma forma de acolhimento. Eis os depoimentos:

[...] o acolhimento acontece no momento em que o paciente dá entrada na UTI, então a gente junto com o paciente também recebe o familiar no sentido de fazer a entrevista desse familiar, coletando dados a respeito do paciente [...] que são importantes para a admissão, e, além disso, passando a questão da rotina da UTI [...]. (ENF 2)

É um relacionamento bastante limitado, a gente só se aproxima no momento da chegada do paciente e, depois, na hora da visita, muitas vezes a gente só chega e pergunta o nome do paciente; a família chega com dúvida, pergunta ao técnico, pergunta ao enfermeiro e o que eu escuto "aguarde que um médico depois da visita vai conversar com vocês"; então é o que acontece de praxe. Esse relacionamento é muito, muito limitado, apenas se pergunta qual é o paciente que vai entrar e quem a família vai visitar; ela entra e visita, fica ali esperando, depois, o médico passa o boletim e a família vai embora, é assim. (ENF 6)

Nesse contexto, o espaço de trabalho das enfermeiras não vem contemplando o aprofundamento do contexto intersubjetivo e predomina a superficialidade da interação, como uma dificuldade pessoal dessas profissionais. Isso é reforçado pela rotina institucional que as obriga a cumprir atividades burocráticas. $\mathrm{O}$ cumprimento das atividades de rotina dentro da UTI e a sua complexidade parecem distanciá-las mais do contato pessoal com seus clientes do que aproximálas, comprometendo, dessa forma, o acolhimento ${ }^{17}$.

Com a sobrecarga de trabalho e as excessivas horas de jornada, as enfermeiras afastam-se dos familiares, tentando falar apenas o necessário, conforme evidenciado no depoimento a seguir:

[...] o tempo já é limitado da família com o paciente, aî a gente não precisa ficar ali, conversando [...] a gente direciona a família para o leito e se tem alguma dúvida, geralmente, a gente sempre pergunta. Eles olham para o monitor e perguntam o que é aquilo, ali, apitando, aí a gente orienta [...]. (ENF 4)

O momento da visita de familiares aos pacientes na UTI é de extrema importância para a atuação das enfermeiras. Com a função de acolhimento e orientação, elas assumem papel de intermediadora entre o paciente e sua família, num ambiente com equipamentos que suscitam a curiosidade dos familiares e das condições estressantes para ambos ${ }^{5}$.

Dessa forma, o acolhimento não é um espaço ou um local, mas uma postura que implica compartilhamento de saberes e envolvimento de uma equipe multiprofissional encarregada da escuta e resolução dos problemas do usuário ${ }^{6}$.

Outro entendimento de acolhimento à família está atrelado ao aspecto organizativo do cuidado, no qual a enfermeira aproveita o primeiro contato com os familiares, após a admissão do paciente na UTI, para obter informações relativas à história de saúde e doença do ente que foi hospitalizado e orientá-los com relação às normas da unidade e esclarecimento de possíveis dúvidas, relativas aos equipamentos da UTI. Eis outro relato:

É um relacionamento bastante limitado, eu acho que a gente só se aproxima no momento da chegada do paciente e depois na hora da visita. Muitas vezes, a gente só chega e pergunta o nome do paciente [...]. (ENF 6)

A rotina institucionalizada tem afastado as enfermeiras dos familiares, apesar do atual estado da arte sobre a família que vivencia a experiência de doença e hospitalização de um de seus membros. $O$ foco da atenção de muitas enfermeiras de cuidados intensivos ainda é centrado no aparato tecnológico da UTI, o que, de fato, potencializa o seu afastamento da família.

\section{Categoria 2 - Relacionando-se com a família na UTI}

Os dados desta categoria evidenciam que, para as enfermeiras entrevistadas, a demanda da unidade potencializa o afastamento dos profissionais de enfermagem da família e o reconhecimento da necessidade de oferecer atenção a esse grupo. De acordo com as 
entrevistadas, a orientação ou conversa informal com a família depende da rotina da unidade, já que esse contato só é estabelecido quando o plantão possibilita.

[...] dependendo da demanda de serviço [...] a equipe dá um aconselhamento, conversa com a família, orienta [...]. Quando a demanda do serviço é grande a gente não consegue [...] então a família é um apêndice, faz parte do paciente; a gente tem obrigação também com a família. (ENF 1)

[...] deveria ter um relacionamento melhor com o familiar dos pacientes [...] (ENF 2)

O processo de trabalho em saúde, principalmente no cenário estudado, tem como um dos seus elementos principais as ações de cuidado, que não deve se limitar à realização de procedimentos técnicos, pois a técnica impessoal e mecanicista pode levar ao distanciamento da pessoa cuidada ${ }^{7}$.

No entanto, as enfermeiras participantes deste estudo mostraram em suas falas que é estabelecido um relacionamento distante com os parentes dos pacientes, o que não está de acordo com a filosofia do cuidado centrado na família. Tal afastamento é decorrente da barreira criada pelos profissionais de saúde, o que só dificulta a possibilidade de uma boa convivência entre ambas as partes.

Os profissionais de enfermagem da UTI utilizam algumas estratégias para se distanciar das famílias, como ausentar-se da unidade para realizar refeições no horário destinado à visita ou permanecer em silêncio durante a prestação da assistência, como evidenciado nos depoimentos:

[...] muitas vezes mesmo a demanda não sendo grande, a gente se ausenta, consegue cometer o pecado de se ausentar, aproveita o momento da visita para tomar um cafezinho, para bater papo com a colega, para ficar sentada, isso acontece [...]. (ENF 1)

[...] a própria equipe cria certa barreira entre o familiar e ele, vai lá cuidar do paciente, faz a medicação e tal, mas sempre com aquela expressão séria, sem falar nada [...]. (ENF 2)

A chegada do paciente na unidade acarreta intervenções rápidas, cronometradas diante do seu quadro de instabilidade, e a família, muitas vezes, não consegue se comunicar com a enfermeira. $\mathrm{O}$ primeiro contato da família com esta profissional na UTI é um momento permeado de profundo sofrimento psicoemocional. É nesse momento que a enfermeira deve se aproximar, orientar a família sobre o estado do paciente e normas e rotinas da unidade, principalmente no que se refere às informações de horários de visita ${ }^{17}$.

Depreende-se desses fatos que a humanização para esse grupo é um desafio. As investidas no acolhimento ainda são bastante tímidas, a estrutura física e organizacional não coopera com a incorporação dessa ação nesse cenário, o que faz supor que o acolhimento, na maioria das UTIs, pode ser estratégia ainda não implementada. Outros estudos poderão trazer mais evidências e confirmar esta inferência, o que não foi objeto deste trabalho.

\section{Categoria 3 - Cuidando da família na UTI}

Acolher a família do paciente, orientar e passar informações sobre o seu estado de saúde faz parte do cuidado que as enfermeiras proporcionam no dia a dia, como relata a enfermeira:

[...] acontece a visita de manhã e à tarde; quando o familiar vem pela manhã, eu tento conversar, se tem alguma dúvida eu tiro, tento chegar próximo para ver se tem alguma coisa; às vezes, ficam apreensivos. Qualquer coisa que aconteça de alteração eles já ficam apreensivos, então eu fico sempre passando por perto para tirar dúvida. Eles ficam muitos ansiosos para ter informações. Mas quando eles vêm pela manhã e até à tarde, antes do médico passar o boletim, eu particularmente passo essas informações. (ENF 2)

O acolhimento no cuidado à família na UTI está ligado ao receber bem e à escuta no atendimento as suas necessidades. Entretanto, é mais do que uma escuta interessada, não devendo ser limitado à recepção das pessoas à porta dos serviços de saúde, pois pressupõe um conjunto contínuo formado por atividades de escuta, identificação de problemas e intervenções resolutivas. As ideias atribuídas pelas enfermeiras ao acolhimento devem ser acrescidas da noção de continuidade, pois receber bem, ouvir e atender às necessidades dos familiares são ações a serem executadas em todos os contatos com os familiares na UTI ${ }^{17}$.

Alguns enfermeiros têm as habilidades de intervenção familiar necessárias para fornecer os membros da família, um apoio adequado durante a crise $^{18}$. Percebese, neste estudo, que certos profissionais se preocupam com o bem-estar da família, diminuindo suas angústias, insegurança, ansiedades, dúvidas e tristezas, ao aplicarem tais cuidados de forma holística e humanizada.

É importante salientar aos familiares que o paciente que vai para a UTI ainda tem chances de viver, como expõe o discurso:

Na prática, a gente procura acalmar, principalmente, quando for a primeira visita! Eles ficam muito preocupados porque acham que ali está correndo sérios riscos, que vai morrer. A gente geralmente tranquiliza; essa parte também é feita pela psicóloga na recepção. (ENF 4)

A informação correta é o caminho mais curto para tranquilizar os familiares; é importante que o ato de humanizar seja praticado por toda equipe multidisciplinar, mas requer embasamento teórico para informar os diagnósticos do paciente, para que este informante não passe uma informação incorreta deixando os familiares ansiosos, nervosos e bastante 
angustiados. Infelizmente, o enfermeiro com a sobrecarga de trabalho elevada não pode fazer muito, mas já faz o suficiente, pois ficam sobrecarregadas de cuidar, informar, acolher, humanizar e, ainda, fazer quase toda a parte burocrática, como afirma a enfermeira:

[...] quando o familiar chega, ele sempre acha que as informações devem ser passadas pela enfermeira ou pelo médico. A humanização não é só isso, até a pessoa que faz a higienização pode ter um tratamento humanizado, mas isso eu acho que demanda vontade, tempo [...] cada dia que passa reduz o número de funcionários e aumenta o trabalho, [...] como é que você vai dar um tratamento humanizado se você não é tratado humanamente, não é? (ENF 5)

São inegáveis os benefícios da tecnologia na UTI, no entanto a dinâmica do trabalho frequentemente conduz os profissionais a vivenciarem situações estressantes, devido à necessidade de conhecimentos especializados. Portanto, é imprescindível atentar para os riscos a que os profissionais de enfermagem estão expostos, com vistas à saúde do grupo e à qualidade do cuidado que prestam à clientela ${ }^{5}$.

Diante dos resultados encontrados, considera-se importante que as instituições formadoras invistam no atendimento das necessidades do cliente, no desenvolvimento de habilidades dos futuros enfermeiros para utilização dos aparatos tecnológicos. É preciso valorizar também o atendimento aos familiares, priorizando a qualidade e a humanização nos ambientes de cuidados críticos, nas áreas hospitalares.

\section{ConClusão}

Na tentativa de descrever com se desenvolve o acolhimento no cuidado, realizado pelas enfermeiras aos familiares de pessoas internadas na UTI, e considerando os limites deste estudo, foi possível depreender desses resultados que o acolhimento é reconhecido por essas profissionais como um espaço de intervenção eficaz, embora ainda não se sintam preparadas para incorporá-lo na sua rotina cotidiana; são investidas pessoais bastante tímidas, já que as estruturas física e organizacional não cooperam com as mudanças desejadas.

A sobrecarga de trabalho das enfermeiras gera um acúmulo de tarefas, levando-as a executá-las de forma técnica e mecânica. Destaca-se a presença de certas enfermeiras com habilidade para esclarecer e orientar os familiares desses pacientes.

\section{REFERÊNCIAS}

1.Simoni RCM, Silva MJP. O impacto da visita de enfermagem sobre as necessidades dos familiares de pacientes de UTI. Rev esc enferm USP [scielo.com.br] 2012 [citado em 29 mai 2015] . 46:65-70. Disponível em: http://www.scielo.br/pdf/reeusp/v46nspe/10.pdf.
2.Maestri E, Nascimento, ERP, Bertoncello KCG, Martins JJ. Estratégias para o acolhimento dos familiares dos pacientes na unidade de terapia intensiva. Rev enferm UERJ. 2012; 20:73-8.

3.Frizon G, Nascimento ERP, Bertoncello KCG, Martins JJ. Familiares na sala de espera de uma unidade de terapia intensiva: sentimentos revelados. Rev Gaúcha Enferm. 2011; 32:72-8.

4.Ramos FJS, Fumus RRL, Azevedo LCP, Schettino G. Rev Bras Ter Intensiva. Políticas de visitação em unidades de terapia intensiva no Brasil: um levantamento multicêntrico [ncbi.nlm.nih.gov] 2014 [citado em 28 de mai 2015]. 26: 339-46. Disponível em: http://www.ncbi.nlm. nih.gov/pmc/articles/PMC4304460/?report=classic doi: 10,5935 / 0103-507X.20140052 PMCID: PMC4304460. 5.Oliveira EB, Souza NVM. Estresse e inovação tecnológica em unidade de terapia intensiva de cardiologia: tecnologia dura. Rev enferm UERJ. 2012; 20: 457-62. 6.Ministério da Saúde ( $\mathrm{Br})$. Política Nacional de $\mathrm{Hu}$ manização: a humanização como eixo norteador das práticas de atenção e gestão em todas as instâncias do SUS. Brasília (DF): Editora MS; 2004.

7.Formozo GA, Oliveira DC, Costa TL, Gomes AMT. As relações interpessoais no cuidado em saúde: uma aproximação ao problema Rev enferm UERJ. 2012; 20:124-7. 8.Ministério da Saúde (Br). Acolhimento nas práticas de produção de saúde. Brasília (DF): Editora MS; 2006. 9.Rusinova K, Kukal J, Simek J, Cerny V. Limited family members/staff communication in intensive care units in the Czech and Slovak Republics considerably increases anxiety in patients ' relatives - the DEPRESS study. BMC Psychiatry. [ncbi.nlm.nih.gov] 2014 [cited in 2015 Apr 10].14: 21. Available from: http://www.ncbi. nlm.nih.gov/pmc/articles/PMC3931312/?report=classic PMCID: PMC3931312

10.Farahani MA, Gaeeni M, Mohammadi N, Seyedfatemi N. Giving information to family members of patients in the intensive care unit: Iranian nurses' ethical approaches. J Med Ética Hist Med. [ncbi.nlm.nih.gov ] 2014 [cited in 2015 Apr 10]. 7:9. Available from: http://www.ncbi. nlm.nih.gov/pmc/articles/PMC4263385/?report=classic PMCID: PMC4263385

11.Ministério da Saúde (Br). Acolhimento e classificação de risco nos serviços de urgência. Brasília (DF): Editora MS; 2009.

13.Silva FS, Santos I. Expectativas de familiares de clientes em uti sobre o atendimento em saúde: estudo sociopoético. Esc Anna Nery. 2010; 14: 230-5.

13. Valadares GV, Paiva RS. Estudos sobre o cuidado à família do cliente hospitalizado: contribuições para enfermagem Rev RENE. 2010; 11(3): 180-8.

14.Bardin L. Análise de conteúdo. Tradução de Luis Antero Reto e Augusto Pinheiro. São Paulo: Edições 70/ Livraria Martins Fontes; 2011.

15.Furuya RK, Birolim MM, Biazin DT, Rossi LA. A integralidade e suas interfaces no cuidado ao idoso em unidade de terapia intensiva. Rev enferm UERJ. 2011; 19:158-62. 16.Salvador PTCO, Oliveira RKM, Costa TD, Santos VEP, Tourinho FSV. Tecnologia e inovação para o cuidado em enfermagem. Rev enferm UERJ. 2012; 20:111-7. 
17. Oliveira CN, Nunes EDCA. Cuidando da família na UTI: desafio de enfermeiros na práxis interpessoal do acolhimento. Texto contexto-enferm. [scielo.com] 2014 [citado em 30 abr 2015]. 23: 954-63. Disponível em: http://www.scielo.br/pdf/tce/v23n4/ pt_0104-0707-tce-23-04-00954.pdf DOI http://dx.doi. org/10.1590/0104-07072014003590013.

18.Tomlinson OS, Peden-McAlpine C, Sherman S. A family systems nursing intervention model for paediatric health crisis. J Adv Enfermagem. 2012; 68:705-14. 